\title{
Tatuaje: ¿Entre el arcaísmo y la moda?
}

\section{Tattoo: Between Archaism and Fashion?}

\author{
Alejandra Walzer Moskovic \\ Departamento de Periodismo y Comunicación Audiovisual \\ Universidad Carlos III de Madrid, España. \\ awalzer@hum.uc3m.es
}

\section{Resumen}

Este artículo aborda un tema contemporáneo, pero con ecos del pasado. En efecto, los tatuajes que vemos hoy en los cuerpos que se exhiben en las calles y en las pantallas pertenecen tanto a la cotidianidad más reciente, que participa de un furor que algunos vinculan con los fenómenos de la moda en la sociedad de masas, como a un registro que se podría denominar arcaico en tanto remite a prácticas asociadas a contextos lejanos respecto de las metrópolis industrializadas. Situar al tatuaje entre el arcaísmo y la moda constituye una hipótesis de trabajo que se abordará por medio de un análisis conceptual de tipo ensayístico y recurriendo también a algunos dichos obtenidos en entrevistas con personas tatuadas y profesionales del tatuaje.

Palabras clave: tatuaje contemporáneo, arcaísmo, moda, identidad, imagen corporal.

\section{Abstract}

This essay deals with a contemporary issue, but with echoes in the past. Indeed, tattoos we see today on the bodies exhibited in the streets and on screens belong both to the most recent everydayness-that participates in a furore that some link to the phenomena of fashion in mass society-as to a record that could be named as archaic since it refers to practices for centuries associated with contexts which are distant to the large industrialized cities. Placing tattoos between archaism and fashion is a working hypothesis to be addressed by a theoretical analysis and also through some testimonies obtained in interviews with tattooed people and tattoo artists.

Keywords: contemporary tattoo, archaism, fashion, identity, body image. 


\section{Introducción}

El fenómeno del tatuaje sobre el que nos referiremos cuenta con una historia extensa. Aunque no procede aquí exponerla en detalle, baste decir que, durante siglos, culturas desconectadas entre sí han practicado diferentes técnicas de marcaje y adorno corporal de carácter ritual cuya existencia se encuentra documentada por medio de la observación, evidencias escritas y artísticas y también mediante hallazgos arqueológicos. Marc Blanchard describe cuatro funciones históricas del tatuaje: función ritual (marca la adquisición de un estatus dentro de la comunidad, es un rito de pasaje); función apotropaica o protectora (ante enfermedades u otros males, también de carácter mágico); función identificatoria (señala al individuo como miembro del grupo y lo diferencia del resto) y función decorativa (vinculada ritualmente con la apariencia personal y el erotismo).

Marcar el cuerpo de una persona por medios permanentes o efímeros tenía un significado comunitario establecido, reglado y compartido. Por ello, existen momentos vitales de transformación individual y colectiva señalados como tiempo idóneo para imprimir una huella corporal. Los motivos y diseños han de ser reconocibles por los miembros del grupo y el acto de marcaje reviste un carácter ritual. Michel Thévoz explica que el tatuaje y otras prácticas como las escarificaciones no constituyen una expresión individual, sino que son una marca de la ley y del orden simbólico de la comunidad en el cuerpo individual. Así, el tatuaje sería una especie de epifanía encarnada que da cuerpo al orden social. Pintar el cuerpo, escarificarlo, perforarlo, insertarle adornos, tatuarlo, son, por tanto, prácticas de orden colectivo que recaen sobre los individuos. Solo el cuerpo deliberadamente marcado es un cuerpo humano. El animal, por contra, cuenta con marcas adaptativas orientadas a la supervivencia o con marcas devenidas de la interacción, como podrían ser las heridas. El ser humano, en cambio, decora deliberadamente su cuerpo y así lo semiotiza, lo hace superficie interpretable, sagrada, poetizada, en fin: humana.

El contacto de Occidente con la práctica del tatuaje, largamente prohibida por las religiones monoteístas, se deriva fundamentalmente de las incursiones coloniales de los imperios europeos en países de América, Asia, Oceanía y África. Los expedicionarios, sorprendidos por sus hallazgos, trasladaron a personas tatuadas de allende los mares para exhibirlas en las metrópolis europeas como curiosidad de feria y muestra de un supuesto salvajismo. Con el tiempo, los marineros que estuvieron en contacto con estas realidades lejanas comenzarán a adoptar para sí el tatuaje y más tarde les seguirán otros colectivos, situados casi siempre en los márgenes de la sociedad y de la ciudad. Así, esta práctica acabará siendo vista y sancionada como indicio de degeneración, peligrosidad o patología. No será hasta los años sesenta del pasado siglo cuando el tatuaje, especialmente en algunas ciudades de los Estados Unidos, comience a ser adoptado por una pluralidad de sectores sociales, impulsado fuertemente por el movimiento hippie. 
Este trabajo tiene, por tanto, el propósito de introducir el debate sobre el estatuto actual del tatuaje partiendo de hallazgos obtenidos en investigaciones previas (Walzer y Sanjurjo; Walzer, "Tatuaje y significado") en las cuales se ha analizado el discurso de personas tatuadas y de artistas del tatuaje detectando que, en la actualidad, fundamentalmente en los argumentos vinculados con la experiencia y el sentido de tatuarse, pueden encontrarse motivos que sin alejarnos de las funciones rituales y simbólicas del tatuaje arcaico adquieren, sin embargo, características particulares de nuestro contexto epocal y social. Por ejemplo, en el predominio del uso del tatuaje como marca de individuación frente a su uso como señal de pertenencia colectiva, más como expresión del yo y de la memoria personal que como encarnación de la identidad y el relato comunitario, o también en la selección de motivos con los que marcar el cuerpo, a veces copiados de prescriptores mediáticos (futbolistas, miembros del star system, etcétera) (Walzer, "El arte en el discurso de los tatuadores"). En todo caso, estos trabajos previos nos han enseñado que, en el seno de la extendida práctica del tatuaje contemporáneo, tan fuerte se oye el argumento antropológico como imperativo resulta abordar un enfoque que indague en el fenómeno contemporáneo del tatuaje como un hecho de dimensión social que se moldea en el espíritu del tiempo presente.

Los dichos de entrevistados que se recogen en este texto proceden de las entrevistas en profundidad semiestructuradas realizadas a hombres y mujeres con edades comprendidas entre los 21 y 61 años en el caso de las personas tatuadas y entre los 23 y 61 años entre tatuadores y tatuadoras. Ambos grupos de personas representan una gran diversidad sociodemográfica y en el caso de profesionales sus experiencias y reconocimiento público es variado (desde tatuadores considerados entre los mejores del mundo hasta aquellos que ejercen su trabajo en los llamados "supermercados del tatuaje" y también aprendices). Los dichos se referirán indicando si corresponden a un hombre $(\mathrm{H})$ o a una mujer (M) y, a continuación, si se trata de alguien tatuado (TT) o tatuador (TR).

Como ha quedado dicho, el tatuaje constituye una práctica que, siendo ancestral, se ha ido moviendo hasta nuestras latitudes y hasta nuestros días con un curioso itinerario que va desde sus significados primigenios hasta la adopción de modulaciones contemporáneas, hoy consideradas como una forma de arte que customiza el cuerpo por medio de un diseño personal que es elegido por quien lo porta y que, en términos generales, expresa aspectos de la vida individual, plasma recuerdos y anhelos, sugiere ideales, preferencias, etcétera (Walzer, “Tatuaje y significado”). Y si bien en ocasiones constituye un elemento de provocación social, también es cierto que la extensión notable de esta práctica la va volviendo menos desafiante y más mainstream (Walzer y Sanjurjo), aunque aún haya quienes continúen expresando rechazo. Un tatuador con su cuerpo amplia y visiblemente cubierto lo expresa como sigue: "el tatuaje es libertad y muchos envidian esa libertad, y muchos que me ven les jode que me ven así porque muchos no pueden o no se atreven a tenerla, porque para ir así por la vida hay que tener una personalidad, hay que tener unos valores, hay que tener una fuerza" (HTR3). 
En entrevistas con personas tatuadas y con tatuadores es habitualmente constatable el afán por hacer del tatuaje una seña de identidad personal, una representación de sí, una narrativización de la vida: “yo no me tatúo por el mero hecho de tatuarme. Creo que son cicatrices en la vida. Yo, cada vez que me ha ocurrido algo importante en mi vida, lo reflejo" (HTT7). A veces se busca por medio de esta práctica la poetización de lo más íntimo y personal: "pensaba que el día de mañana tengo que tener unas alas en la espalda, el sentir la libertad de volar. Entonces cuando me he sentido más libre me he dicho: tengo que hacérmelo" (MTT5). En otras ocasiones se persigue un valor de reivindicación acorde con la propia moral o ideología: "es una forma de reivindicar a través de tu cuerpo, ¡y ya está!, entonces puse: esta es mi piel y a quien le guste bien y a quien no le guste, tampoco es un problema" (MTT2).

No solo el paso del significado ritual colectivamente codificado al tatuaje individualizado y subjetivizado diferencia a la práctica ancestral de la contemporánea, también hay algo del orden de la temporalidad que se altera, puesto que el acto de tatuarse es hoy el resultado de una elección. En tanto tal, no tiene lugar en momentos colectivamente pautados, sino que depende de factores íntimos, de un timing subjetivo: "el primero es uno pequeñito que está ahí en medio y que me hice a los veinte años porque me gustaba" (MTT11), explica una chica. Estas diferencias respecto del tatuaje ancestral pueden leerse como algo coherente con la deriva individualista y personalista de las sociedades y los contextos en los que habitamos. El hecho de que hoy el tatuaje responda mayoritariamente a una decisión asumida por un sujeto que escoge si se tatúa o no, que decide qué es aquello que se hace escribir o dibujar sobre la piel, en qué momento de su vida le parece oportuno, si el tatuaje será visible o por el contrario quedará cubierto por la vestimenta, entre otros factores, lleva a valorar, al menos a primera vista, que la actual práctica del tatuaje se encontraría en las antípodas del tatuaje tradicional. Sin embargo, es preciso examinar con mayor detenimiento para saber si tras estas divergencias de entrada subyacen puntos de contacto, una especie de parentesco o lazo aún audible con la práctica ritual de marcación corporal practicada por culturas ancestrales.

Evidentemente, factores tan frecuentes hoy como el contacto con personas tatuadas, la presencia pública y mediática de famosos exhibiendo sus tatuajes añadida a la programación televisiva de reality shows que tienen al tatuaje por tema monográfico; también la publicidad, la gran cantidad de contenidos online e incluso algunos elementos de la moda del vestido, han dotado al tattoo de un nuevo prestigio o, incluso, de un aura de actualidad asociable a la moda como fenómeno capaz de encarnar lo estéticamente deseable. Y así se entrelazarían aspectos que hacen del tatuaje un elemento en el que laten ecos del pasado, en el que se expresan tendencias sociales contemporáneas, en el que se encarnan aspectos individuales y en el que también se expresan aspectos del gusto colectivo, como dice un entrevistado: "la verdad es que es una pena decirlo pero somos muy borregos en todo, cuando hay una moda la gente la sigue, es una pena, pero luego a lo mejor empieza por moda y acaba siendo como un estilo de vida, por así decirlo" (HTR14). 
Entre lo atávico y la moda, entre lo colectivo y lo individual, se encuentra la interrogación que se pretende abordar aquí al pensar en el auge del tattoo en nuestras sociedades. Partimos de ideas ordinarias y bastante generalizadas que asocian lo atávico con aquello que corresponde al pasado lejano, quizás al pasado de la especie y que, en tanto tal, constituye un dato poco provisto de actualidad, algo audible si acaso como una resonancia lejana y difusa. Además, la moda se vincula al presente rabioso, a la estética y al mercado, por lo que su temporalidad es corta y está destinada a la caducidad y la subsiguiente renovación.

Entre estos extremos de partida, ¿dónde alojar nuestro discernimiento sobre el fenómeno del tatuaje con el que nos topamos hoy?, ¿es el tatuaje una práctica atávica o de moda, o ninguna de las dos, o ambas al mismo tiempo? Preguntas todas que se irán desplegando en un intento de reflexión conceptual que esperamos que permita complejizar estas ideas iniciales.

\section{Lo atávico}

Sin lugar a dudas nuestro interés en torno al tatuaje contemporáneo tiene un antecedente ineludible en el trabajo antropológico sobre las culturas primigenias. La etimología latina del término atavismo refiere a lo ancestral, es decir, al origen remoto. Origen y genealogía comparten la partícula "gen", que alude a la transmisión de caracteres hereditarios. La alta carga biológica de este término no resulta aplicable desde nuestra perspectiva al estudio de fenómenos culturales, pero, sin embargo, nos sitúa en el campo semántico de aquello que, vinculado con el pasado, se hace presente de forma repetitiva a lo largo del tiempo. Y en efecto, en el ámbito de la cultura, se suele denominar como atávico a lo que pertenece a un registro lejano vinculado a los orígenes. El adjetivo atavismo se emplea para señalar que algo refiere al complejo de conductas identificables con las formas propias de las culturas del pasado. Desde la perspectiva occidental, lo atávico ha sido frecuentemente asociado a lo primitivo más que a lo histórico y ha teñido una cierta visión evolucionista sobre el humano, la sociedad y la cultura que abonaba la hipótesis del progresivo perfeccionamiento con un consecuente abandono de las formas primigenias por ser menos adecuadas adaptativamente o menos sofisticadas como producción de la humanidad. La calificación de algo como atávico queda, por tanto, fuertemente connotada.

El renacimiento del tatuaje en el siglo $\mathrm{xx}$, fundamentalmente a partir de la década de los sesenta, va de la mano de sectores sociales que lo emplearon como una forma de reivindicación (por ejemplo, del derecho a decidir sobre el propio cuerpo), como crítica política y social (por ejemplo, para incomodar al gusto burgués) o incluso como una forma romántica de vuelta a las raíces. Es en este contexto que surgen los conceptos de modernos primitivos y de neotribalismo, ambos implicando ciertas prácticas que se postulaban como una propuesta alternativa a una sociedad vivida 
como deshumanizadora. Roland Loomis, autodenominado Fakir Musafar, gran aficionado a diversas prácticas de modificación corporal, acuñó en 1978 el término, en apariencia contradictorio, de modernos primitivos de gran influencia en diferentes subculturas y que llevó a muchos jóvenes a usar su piel como forma de expresión y a experimentar en aspectos prohibidos del cuerpo.

En 1989 V. Vale y Andrea Juno publicaron Modern Primitives, libro en el cual examinan el enigma contemporáneo del renacimiento de prácticas corporales arcaicas con un carácter notoriamente visual, que sintetiza las antiguas tradiciones tribales con las costumbres urbanas modernas buscando una nueva integración en un contexto al que consideran altamente alienado. El deseo de cambiar el mundo en busca de una sociedad ideal encontraría una forma de expresión por medio de la modificación de aquello sobre lo que se tiene poder: el propio cuerpo.

Victoria Pitts explica que ya desde el siglo xix hubo quienes vieron al primitivismo con nostalgia. Con los procesos modernizadores la idea de lo primitivo fue asumida como aquella capaz de encarnar lo auténtico, lo que no estaba tocado por los intereses industriales. El primitivismo consistía en asumir una vida más natural y alejada del constreñimiento del mundo lineal del avance científico y material de las sociedades occidentales. Se produjo entonces una suerte de fetichización de lo exótico y en el contexto de la crítica a los modos occidentales, lo atávico apareció como más puro, más próximo a las esencias, más natural y comunitario. Así planteada, la intersección entre primitivismo y modernismo resulta interesante, pero pone en evidencia una concepción romantizada de lo atávico que lo expone como un lugar idealizado y perdido, una arcadia a la que habría que retornar.

Aquellas sociedades a las que se ha llamado primitivas, caracterizadas como agrupamientos humanos carentes de escritura y medios mecánicos, fueron las que inicialmente prefirieron estudiar los antropólogos. Sin embargo, desde hace décadas, se ha producido una transmutación que ha añadido el interés por las sociedades contemporáneas, como queda expresado en el curso "La antropología frente a los problemas del mundo moderno" que Claude Lévi-Strauss impartió en 1986 en Japón. Coincide Marc Augé explicando que, en el actual estado del mundo intercomunicado, el estudio de grupos restringidos en lo geográfico, lo histórico y lo político va dando lugar al interés por las sociedades contemporáneas en un nivel planetario. El estudioso ya no solo observa al otro, al salvaje, al primitivo, sino que, con el "pasaje de la colonización a la globalización" (10) todos nos hemos convertidos en potenciales aborígenes de la observación antropológica. Ciertamente, la indagación en torno al tatuaje actual nos sitúa en esa posición que invita a una dialéctica entre lo antiguo y lo contemporáneo, entre lo local y lo global.

Para Régis Debray hay una relación de partida doble entre los fenómenos de progresión y los de regresión, así en el decurso de la humanidad cada "progreso técnico provoca un reequilibrio étnico" (54). Para él, más que un enfrentamiento entre "lo sagrado y lo profano, lo irracional y lo racional, el arcaísmo y la modernidad, lo mundial 
y lo local" (53), lo que existe es un principio de constancia que buscaría reequilibrios compensatorios y que también está sometido a la ley del retorno. Así es que propone no olvidar que el primate de la sabana seca es el soporte actual del hombre cibernético y, en consecuencia, la historia de la humanidad no sería un proceso irreversible de secularización que expulsaría lo sagrado de su seno, sino una relación constante entre pares (a veces planteados como antitéticos) que en algunas épocas se encuentran más equilibrados y en otras, menos. Por tanto, el origen no constituiría algo que ha de mirarse echando la vista atrás porque "el origen está presente para nosotros en todo momento, visible, obstinado" (55). Existiría con nuestro pasado original una relación que no es, por tanto, de anterioridad, sino una lógica de prioridad. Observando fenómenos contemporáneos en los que lo folclórico adquiere nuevos prestigios en las ciudades, en los que la laicidad avanza, pero surgen fidelidades a filosofías varias, esoterismos, idolatría de artistas y deportistas, gurúes surtidos, etcétera, se pregunta: “¿por qué nuestro pasado más arcaico invade cada vez más pesadamente nuestra modernidad?, ¿por qué se nos acerca si según el calendario nosotros nos alejamos de él?" (56). Esta pregunta es de gran interés para pensar el fenómeno contemporáneo del tatuaje, porque para este autor nuestras sociedades adoptan nuevas formas para lo sagrado, no lo expulsan de su seno, sino que producen una operación consistente en desarticular lo instituido respecto de lo instituyente.

Si antes se mencionaba el origen latino del término atávico, en su acepción griega arché alude a comienzo y punto de partida, pero también es mando y poder. Así, lo arcaico no sería "un lugar en el tiempo sino un escalonamiento de las determinaciones; no lo superado sino el sustrato; no lo caído en desuso sino lo profundo; no lo perimido sino lo reprimido" (Debray 58). En esta concepción, pues, pensar el auge del tatuaje contemporáneo no nos situaría en un simple retorno de prácticas pasadas sino en la de la emergencia de lo reprimido, la presencia de lo instituyente, la visibilización del sustrato.

\section{¿Sociedades primitivas y sociedades modernas?}

Ahora bien, si consentimos en entender que lo atávico constituye una base común del ser humano que modula su expresión según situaciones sociales particulares, también es necesario aclarar qué entendemos por sociedades primitivas y sociedades modernas. Las sociedades calificadas como primitivas son aquellas cuyos integrantes las tienen por entidades que deben perdurar y, para ello, deben conservarlas, reproducirlas y transmitir sus principios, algo que se realiza por medio de diferentes mecanismos, entre ellos, los ritos y los rituales. Margaret Mead las llamó "sociedades posfigurativas" porque las figuras de valor se encuentran atrás, provienen de los ancestros, y las nuevas generaciones están abocadas a reproducir sin diferencia el tesoro heredado. En general, se trata de sociedades ágrafas y con poca orientación hacia la técnica, cuya apertura hacia el exterior y su inclinación al cambio es muy reducida y poco 


\section{FIGURA 1}

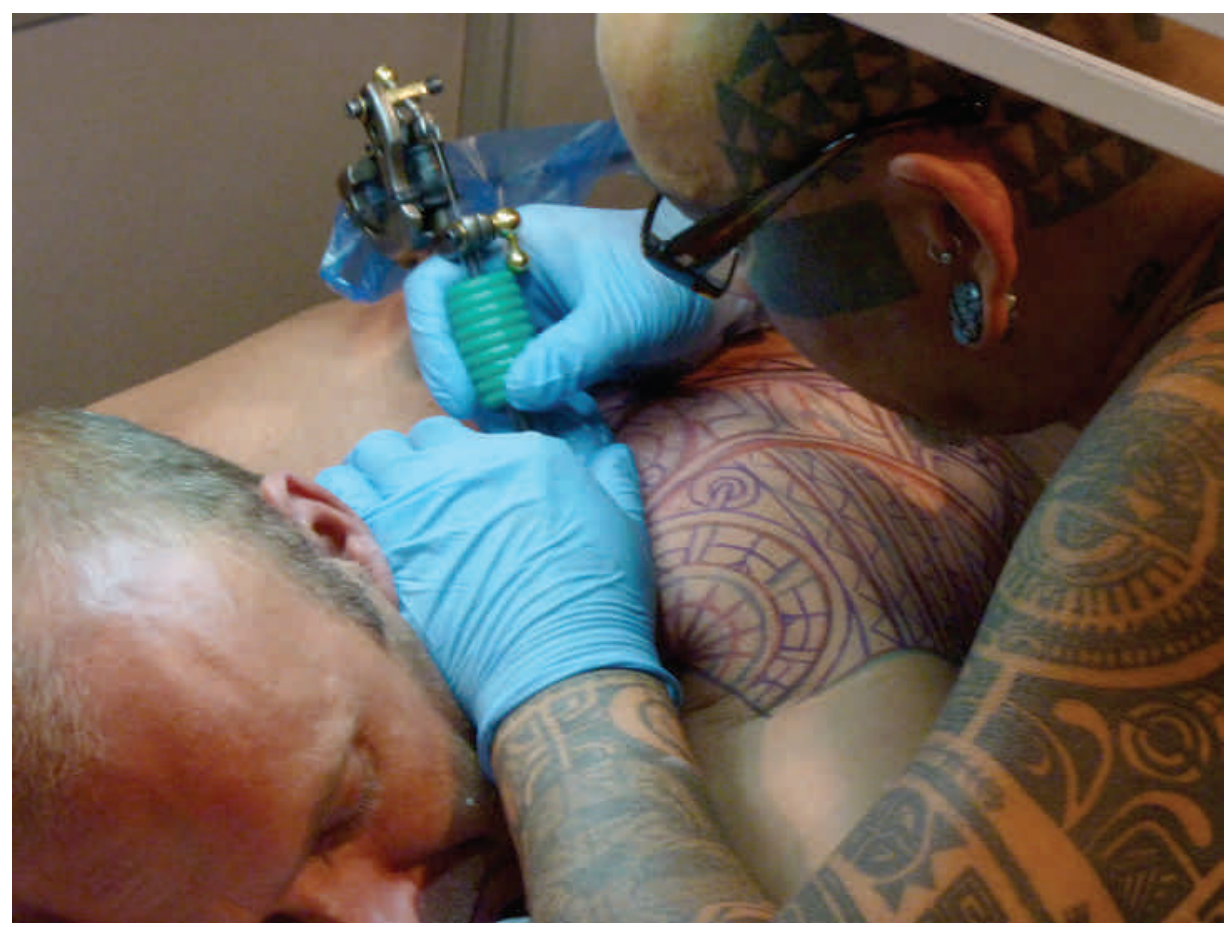

Chime, maestro del tatuaje maorí en MulaFest de Madrid, 2013. Foto: Alejandra Walzer.

entrópica. Las sociedades modernas, sin embargo, se encuentran regidas por la puesta en práctica del derecho universal a la alfabetización, la alta tecnificación, el prestigio de la novedad, el cambio permanente y en ellas hay mucha diversidad y desorden al tiempo que, al menos en apariencia, lo ritual y lo colectivo van decayendo mientras se ensalza el practicismo, el individuo y su singularidad. Mead las denominó "prefigurativas" puesto que su modelo está adelante, en el futuro, no se espeja en los padres sino en los pares y aún no tienen una figura definida.

Sin embargo, como acabamos de exponer, en los últimos años diversos autores han comenzado a leer nuestro tiempo desde una nueva perspectiva que no establece fronteras tajantes entre ciertos modos que se llamaron primitivos frente a los modernos. Martine Segalen, por ejemplo, llama la atención sobre la polémica entre quienes ven a las sociedades contemporáneas como carentes de ritos y aquellos que los ven en todas partes. Según la etnóloga: "sin ser elementos sociales clave, los rituales participan del funcionamiento de nuestra sociedad" (37), algo que se hace evidente, por ejemplo, en el resurgimiento de ciertas celebraciones religiosas y todo tipo de expresiones públicas, en algunas fiestas, actuaciones y espectáculos multitudinarios cargados de emotividad. 
Michel Maffesoli lleva ya algunas décadas trabajando en este sentido, fundamentalmente en sus obras El tiempo de las tribus, El instante eterno y El reencantamiento del mundo. En esta última postula que "las idea-fuerza' que actúan en nuestras sociedades, tan evidentes que ya no las vemos, son justamente la activación y la integración en la vida diaria de esos viejos arquetipos que actualizan sus energías y las potencialidades del inconsciente colectivo" (72) y menciona ejemplos como la publicidad, la música, el cine o diversas teatralidades urbanas en las que "nos enfrentamos a un proceso de anamnesis de cosas que habíamos creído superadas. Las criptas y cavernas de nuestra naturaleza humana" (72). Estas expresiones evidenciarían una saturación del idealismo y de la consciencia de sí y una suerte de "retorno del misterio", un "compartir los mitos, religancias comunitarias, lenguajes específicos, reactualización de la iniciación" (74) que a veces aparecen personificados totémicamente mediante stars, que son la última moda pero que encarnarían figuras prototípicas vestidas de nuevas características y que, a pesar de su apariencia novedosa, pondrían en escena una afectividad primaria. Evidentemente, no se postula aquí una vuelta al primitivismo al estilo de los modernos primitivos como proponía Fakir Musafar, sino que se pretende hacer notar que, en tiempos de cambio o de crisis, se hace manifiesto cierto "dinamismo interno que prevalece en las interacciones societales" (Maffesoli, El reencantamiento 99). Marc Augé concuerda con esta perspectiva dialéctica: "la reactivación de la vida ritual es una necesidad vital; solo ella permite escapar al aislamiento mortífero y a la regresión que mitifica el tiempo de los comienzos. Tenemos necesidad de la relación con el otro y, por ende, con el porvenir" (127).

Entonces, frente al ideal cartesiano y al sujeto individual de la modernidad, se estaría gestando un individuo más pluralizado, un sujeto que se disuelve en los múltiples grupos de los que participa en una ola de tribalismo que caracterizaría a la nueva sociedad configurada a partir de la posmodernidad.

¿Hay algún lugar dentro de estos postulados para la comprensión del fenómeno contemporáneo del tatuaje como práctica de adorno corporal significante que prolifera de forma nunca antes vista en nuestras sociedades? Dejamos la pregunta formulada y a continuación vamos a intentar formalizar conceptualmente la cuestión de la moda, que constituye otro de los conceptos clave de este argumento orientado a dilucidar cuestiones que permitan situar al tatuaje contemporáneo.

\section{La moda}

Cuando aludimos a la moda, en términos generales, lo primero que aflora es su relación con el vestido y en efecto así es, aunque el sistema de la moda abarca un repertorio amplio de objetos, usos, estilos, pensamientos y conductas que se caracterizan por responder al espíritu de una época. La moda no es un fenómeno que haya existido siempre, de hecho, hay pueblos y sociedades sin moda donde la indumentaria esta- 
ba estrictamente codificada de forma casi inmutable, como es el caso de la antigua sociedad china (Barthes 412). Tal y como la conocemos hoy, la moda constituye un fenómeno propio de la modernidad industrial, y si bien ciertos autores sitúan sus orígenes hacia finales de la Edad Media, el impulso industrialista ha sido determinante para el desarrollo de un sistema extenso y polifacético como el que conocemos. La moda es, por tanto, "una formación esencialmente sociohistórica circunscrita a un determinado tipo de sociedad" (Lipovetsky 24) y lo propio de ella es la variación, la caducidad, la producción en serie, el prestigio de lo nuevo e incluso de lo extranjero. Con estas peculiaridades, la moda tiende a la renovación, a la diversidad y al abandono de la idea del pasado como algo inmutable.

Aunque la moda afecta a amplios sectores de la vida, la referencia al aspecto personal por medio del ornamento del cuerpo y la vestimenta parece ser un ámbito prioritario de interés. Para Barthes la moda es un sistema de signos mediante el cual se emiten comunicaciones: "llevar un traje es fundamentalmente un acto de significación, más allá de los motivos del pudor, adorno y protección. Es un acto de significación y, en consecuencia, un acto profundamente social" (419). También Baudrillard explica que los objetos dan satisfacción a necesidades humanas sociales que traspasan sus meras competencias funcionales, concordando en este punto con Barthes.

El fenómeno ha de ser contemplado, por tanto, desde perspectivas múltiples que, sin desdeñar la enorme importancia económica que la industria de la moda pone en funcionamiento y que constituye una de sus aristas sobresalientes, permitan advertir los aspectos sociales involucrados en "las incesantes variaciones y el aumento de fantasías que definen propiamente la moda” (Lipovetsky 57).

Para Georg Simmel en la moda coexiste una tendencia imitativa con otra de signo renovador, una tendencia a la identificación con el grupo social al tiempo que la búsqueda de la individualidad, permitiendo así "conjugar el interés por la permanencia, la unidad y la igualdad con el interés por la variación, la particularidad y la singularidad" (27). Estas tendencias de signo opuesto son presentadas como la disyuntiva entre la imitación y el apego a lo existente, de un lado, y la búsqueda de lo cambiante, lo nuevo y lo propio, de otro. Un hombre tatuado lo refiere así al explicar sus razones: "todos tenemos la necesidad de pertenencia, de sentirte identificado con alguna cosa y al mismo tiempo la idea de ser tú mismo, tú mismo y diferente a los demás" (HTT1).

Justamente el carácter imitativo de la moda (inicialmente respecto de los estilos aristocráticos) y la satisfacción que este puede proveer, se deduce -en parte- de su capacidad para concitar el apoyo social. Ahora bien, el desarrollo contemporáneo de la moda y sus ritmos económicos han hecho que los bienes se produzcan deliberadamente "con la finalidad de que se pongan a la moda" (Simmel 30). Esta es una consideración relevante puesto que evidencia un estado de cosas y porque además, entre sus consecuencias, hay una que nos interesa especialmente y es que en sociedades en las que la novedad y el cambio constituyen valores bien ponderados, el ritmo se 
FIGURA 2

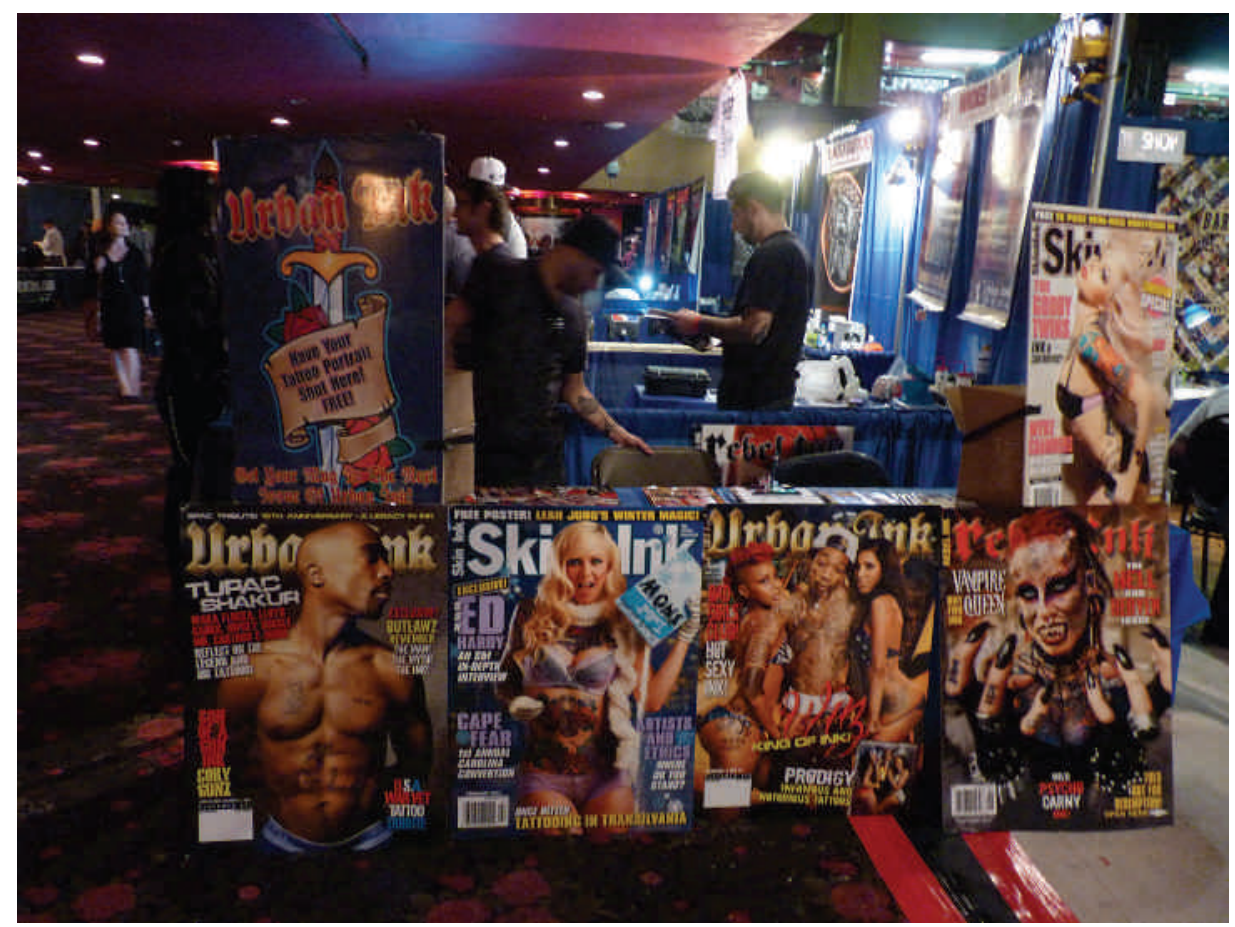

Portadas de revistas especializadas en tatuaje. Foto: Alejandra Walzer.

torna veloz, incluso cada vez más precipitado, haciendo que la necesidad de cambiar de pareceres y gustos se imponga según una temporalidad cada vez más corta: lo que es de rabiosa actualidad en un momento tiene como destino prefijado el pasar y ser sustituido, volverse pasado, que es también volverse pasado de moda.

La moda que hoy conocemos se caracteriza, pues, por una multiplicidad de elementos que la posicionan entre la identificación con lo colectivo y con la individuación. Es un elemento potente y generalmente visible de significación personal y también alberga aspectos vinculados con la sustitución perentoria al ritmo de los intereses económicos.

Para Simmel, "la forma de vida conforme a la moda extrae su carácter específico de la destrucción de cualquier contenido anterior, y posee una peculiar homogeneidad en la que resultan inseparables la satisfacción del impulso destructivo y el impulso a acceder a contenidos positivos" (40). Justamente este punto es el que torna compleja la liquidación del debate sobre la actual extensión de la práctica del tatuaje como si fuera un mero asunto de "estar a la moda" puesto que, salvo en el caso de las excepciones en que las personas eliminan un tattoo, la cualidad indeleble del mismo una vez fijado sobre la piel le niega esa posibilidad de sustitución o destrucción. Y si 
bien es cierto que la remoción por medios médicos es posible, ello no es así en todos los $\operatorname{casos}^{1}$ ni siempre se consigue con resultados satisfactorios. La opción de cubrir y transformar un tatuaje (cover) que ya no se desea porque no gusta, no representa al sujeto, se ha ido modificando de una manera poco feliz sobre la piel, está mal hecho, o alude a personas o situaciones que se desean olvidar, es posible y de hecho ocurre $^{2}$ pero, en todo caso, quienes cubran y disimulen un tatuaje anterior ya no serán personas sin tinta en la piel. En la mayoría de los casos tatuarse es un punto sin retorno. Al mismo tiempo, como los estilos artísticos en los que se efectúan los tatuajes también están sujetos a modificaciones y modas, un cuerpo tatuado podría convertirse en un catálogo de temporadas pasadas. Hay algo en la transitoriedad y en la posibilidad de ser infiel a la moda que le da un punto especialmente atractivo, pero que en el caso del tatuaje funcionaría de una manera diferente. En la moda del vestido se sustituye una prenda por otra, en el tatuaje lo más factible es que se vayan añadiendo más dibujos sobre la piel en una coexistencia aditiva de estilos y significados. En consecuencia, si bien es cierto que en algún sentido tatuarse se ha vuelto una práctica que comparte algunas peculiaridades con la moda, hay ciertos aspectos que la alejarían de aquellas características que, con carácter general, permiten caracterizarla.

\section{¿La muerte de la moda?}

Ahora bien, la socióloga Susana Saulquin ha postulado en los últimos años que la moda tal como ha sido planteada y en el contexto del sistema que conocimos "está en los comienzos de su desarticulación" (15) y ello es así porque la dialéctica de la modernidad y la industrialización en la que el actual sistema floreció a niveles antes impensados se encuentra en un evidente declive de la mano de fuertes transformaciones sociales, políticas, económicas, estéticas, en el contexto de la globalización y de la masificación de internet. Además, desde un punto de vista de los gustos sociales, estaría formándose progresivamente una especie de agotamiento, de cansancio, de rechazo de los códigos de lo uniforme que promueve lo masivo. En consecuencia, el ser humano estaría hoy en la búsqueda de lo que es más personal, lo que lo individualiza y lo singulariza. Así, en detrimento de la moda masiva e industrial van surgiendo en los últimos tiempos, y cada vez más, producciones que se pueden catalogar como semiindustriales $u$ otras que en ocasiones suponen una vuelta a lo artesanal y a los estilos del pasado y que pueden observarse estéticamente también en cierto retorno planteado por las tendencias vintage. Estos nuevos criterios de gusto y estos tipos de

1 Con las actuales técnicas los colores azul y verde presentan dificultades para su eliminación debido al tipo de pigmentos que llevan, también los tatuajes grandes ofrecen problemas para su remoción total, así como aquellos situados en la espalda, los brazos o las piernas donde la piel es más gruesa y la tinta penetra más profundamente.

2 Numerosos reality shows tienen estas circunstancias por tema monográfico: "Bad Ink", "America’s Worst Tattoo", "Tattoos After Dark", “Tattoo Nightmares", entre otros. 
producción son asimismo contemporáneos de un modelo estético al que se llama étnico, y que está obteniendo una visibilidad creciente.

Lo que subyace en las producciones artesanales es la oferta de alternativas para quienes buscan lo personalizado, entendido como aquello que es capaz de expresar las diversas maneras en las que la gente se ve a sí misma y las formas en las que se quiere dar a ver. Ello no es ajeno a corrientes sociales presentes en otros ámbitos de la vida, por el contrario, es "consecuencia de la crisis de los discursos modernos [que] impulsa a la reapropiación de la capacidad de gestión de la propia vida, que hasta el momento se depositaba en la sociedad" (Saulquin 75). Resulta interesante observar que simultáneamente con estos fenómenos en el mundo de la moda surgen también de forma paulatina y paralela nuevas figuras ad hoc: personal shoppers, bloggers de moda y otros personajes y recursos orientados hacia la comunicación personalizada en materia de vestido y apariencia personal.

Es este el escenario en el que Susana Saulquin anuncia la muerte de la moda, pero especula sobre el día de después. Entre los numerosos elementos que pueden conducir a un porvenir nuevo que sea la superación del sistema centralizado y autorregulado se deben contar factores de orden tecnológico a los que les da un peso notable porque afectan a las relaciones sociales al tiempo que tienen incidencia sobre el ámbito motivacional de los sujetos. Estamos en un momento de cambio y transición en el que la moda masiva coexiste con estos movimientos emergentes, pero el salto hacia el futuro, que viene de la mano del avance tecnológico, está dando lugar a lo que ella caracteriza como "una recuperación espiritual" (124), entendida como aquello que permitirá dejar atrás la dualidad objeto/sujeto, propia de la modernidad. Se trataría de nuevas modalidades que implican "un retorno a la vivencia del hombre primitivo" (124), un "retroprogreso" (7) cuya característica más saliente será la recuperación de lo espiritual que se trasladará a diversos ámbitos de la vida y también al valor simbólico del vestido y la apariencia personal. En definitiva, la estructura de la moda moderna habría funcionado como una imposición exógena y, en tanto tal, impulsora de un cambio pautado estilística y temporalmente por medio de los mecanismos de seducción capaces de generar deseo y consumo acorde a los intereses mercantiles. Este estado de cosas está cambiando como consecuencia de una multiplicidad de factores, algunos de los cuales ya han sido referidos y que serían coadyuvantes en "el paulatino proceso de individualización que impulsa a ungir los personalismos digitados por auténticos hombres y mujeres, que buscan más satisfacer sus necesidades específicas que los deseos colectivos" (Saulquin 25). Dice un hombre tatuado, al respecto: “ahí entra la globalización, porque ahora los individuos ya no somos individuos, somos el todo, entonces el tatuaje nos vale para identificarnos, es como decirte: ¡perdona, yo soy yo y no soy como los demás!, entonces yo puedo estar tatuado como él, pero nunca su tatuaje va a ser como el mío" (HTT2).

Como consecuencia de estos movimientos, la moda como sistema autoritario se desarticularía paulatinamente al tiempo que el desarrollo de la tecnología digital iría permitiendo que un cuerpo desnudo frente a un ordenador se reinvente en múltiples 


\section{FIGURA 3}

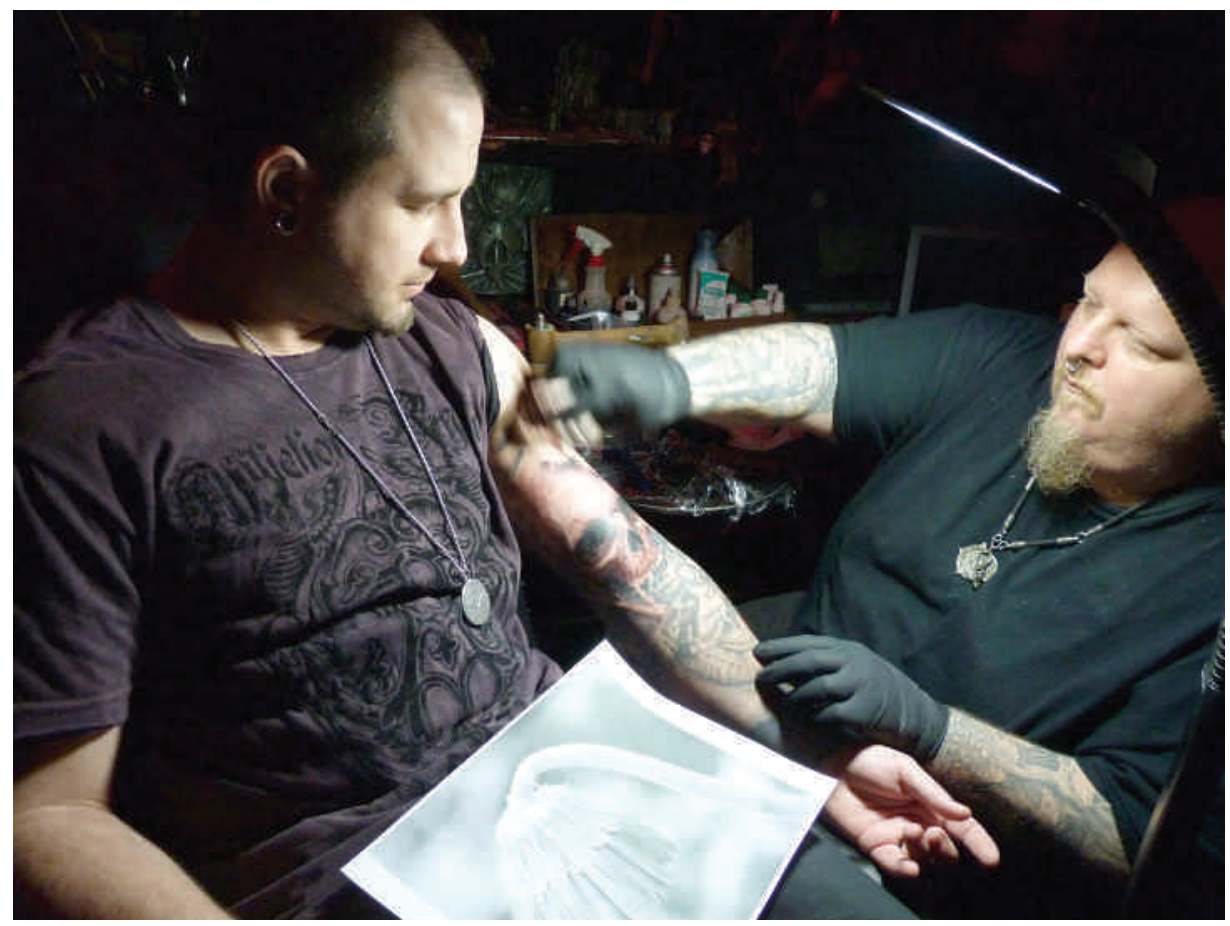

El reconocido artista Paul Booth tatuando en su estudio de Nueva York. Foto: Alejandra Walzer.

imágenes posibles. Así, se pondrá en escena una suerte de espiritualidad vinculada con la apariencia haciendo que la forma de verse comulgue con la identidad asumida o que sea una forma de búsqueda personal, de construcción identitaria. Por tanto, lo que estaría en juego ya no sería solamente diseñar la propia vestimenta o adornos, sino que se trataría de un proceso de búsqueda que lo que persigue es "diseñarse a sí mismo" (Saulquin 31). Una operación compleja, sin dudas, pero que ya está teniendo lugar y no solamente en el ámbito de la vestimenta, sino también de los cuerpos, como es evidente en la proliferación de cirugías estéticas, body buildings, cyborgs, gadgets adheridos al cuerpo y a la ropa, en el auge de todo tipo de modificaciones corporales como tatuajes, perforaciones, implantaciones, etcétera.

En el caso del tatuaje, esta búsqueda es muy evidente y palpable si examinamos los dichos de personas tatuadas: "me dicen por el signo del uranio: ¡ay! Eso es porque eres una chica radioactiva..." (MTT3). Aquí el tatuaje del símbolo químico del uranio que tiene su origen en los estudios sobre ciencias ambientales realizados por esta joven mujer deviene en un doble signo de identidad: el profesional y el que se le atribuye por sus características psicológicas de mujer fuerte y reactiva.

La tecnología aplicada a la industria del vestido, de las comunicaciones y de la medicina tiene un rol evidente en este estado de cosas, pero también lo tiene el masaje 
de la moda y sus comunicaciones intensivas que durante largo tiempo han fomentado lo que Lipovetsky denomina "una trastocación del propio ser, una autobservación estética sin precedentes" (41). Este estado de vigilancia personal de la apariencia ha asaeteado el narcisismo y la vanidad hasta el punto de convertirse, para algunos, en una meta existencial. Pero, de otro lado, la democratización de la moda y la reciente dilución de las fronteras de lo que es demodé, han permitido que las personas empiecen a sentirse más libres en cuanto a sus elecciones y menos constreñidas por las presiones sociales homologadoras que, aunque no desaparezcan, se relajan volviéndose progresivamente más tolerantes.

Cabría preguntarse ahora si en estos movimientos tan ampliamente generalizados de la moda y las consideraciones sobre el declive del sistema y sus consecuencias, podemos situar el auge contemporáneo del tatuaje, es decir, entre lo atávico y lo moderno, entre el impulso imitativo y la búsqueda del sello personal, entre lo duradero y lo perecedero, entre la moda y la posmoda.

\section{Tatuaje: ¿entre lo arcaico y la moda?}

Las prácticas de transformación corporal que se han tornado múltiples y multiplicadas en nuestro contexto muestran que el cuerpo está hoy presente de forma importante en nuestras nociones de selfy de comunidad. Hay una confluencia de determinaciones y factores que convergen en el hecho real y actual por el que las imágenes virtuales, las técnicas médicas y las tecnologías de la representación permiten construir identidades y cuerpos que atraviesan fronteras antes intactas, como ha sugerido Pitts. Más allá de elecciones personales que son determinantes y fundamentales, no es posible soslayar el hecho de que esas decisiones tienen un sentido social y que esas transformaciones corporales forman parte del capital cultural y de un espíritu de la época. Así, Michael Atkinson afirma que si bien el acto de tatuarse es altamente individualista constituye esencialmente un conjunto de fenómenos que involucra una letanía de actores sociales conectados (xi). El tatuaje, que hemos situado inicialmente como marca tribal, es también actual y reviste en nuestro contexto características específicas y diferenciales tanto respecto del tatuaje aborigen como también respecto de otras prácticas de modelación o transformación del cuerpo muy en boga hoy, y ello es así por su origen, su potencial semiótico y su carácter permanente.

Lo cierto es que "todas las culturas imprimen su marca al cuerpo: mediante estilos de trajes, peinados y adornos, mediante mutilaciones corporales y mediante comportamientos gestuales" (Lévi-Strauss 154). En términos generales, se puede afirmar que la apariencia, aun cuando sea consecuencia de una búsqueda personal, no puede ser considerada como algo exclusivamente individualista, sino que está en relación con la mirada del otro y con un abanico multicolor de factores sociales y epocales de sutil presencia y peso. 
Determinar con exactitud la medida en la que el tatuaje se ha extendido en las últimas décadas es algo muy complejo. Statistic Brain ha publicado en abril de 2015 un estudio según el cual el 14\% de estadounidenses (45 millones de personas) tienen al menos un tatuaje. Este porcentaje tiene expresiones interesantes si se lo analiza por segmentos de edad, así, entre los 18 y 25 años la cifra asciende al 36\% y entre los 26 y los 40 se eleva hasta el $40 \%$ de la población. ${ }^{3}$ Y aunque estas cifras no son en absoluto concluyentes ni definitivas, ni necesariamente indicativas de una generalidad, resultan altamente sugerentes.

Para Maffesoli, en las megalópolis se estaría produciendo un "sorprendente retorno de los valores arcaicos al primer plano social” y esto funcionaría, a su vez, como un indicador de otro retorno: el de lo trágico entendido como "lo no dicho ensordecedor" (El instante eterno 9). Numerosas prácticas juveniles en sinergia con el desarrollo tecnológico, una voluptuosidad profunda y el mimetismo tribal serían modos mediante los cuales lo trágico se expresaría hoy, poniendo en evidencia la actual consciencia de la precariedad de la vida. La avidez por vivir es lo que acaba situando a los sujetos entre lo trágico y el hedonismo. Una avidez y un hedonismo capaces de llevar a un estado que es un más allá del consumo y al que Maffesoli denomina “consumación” (25).

Para este autor los arcaísmos son hoy "vueltos a pensar en función del presente, vividos de manera específica, pero que no por ello conservan menos la memoria de los orígenes [...]. Lo que es vivido cualitativamente, con intensidad, se dedica a hacer resurgir lo que ya estaba ahí, en el seno mismo del ser, sea este individual o colectivo" (29). No se trata pues, a la manera de los modernos primitivos arriba citados, de retornar a un pasado idealizado para despojarnos de los males que nos infringe la sociedad tecnológica y mercantilizada, sino que la práctica del tatuaje encarnaría una expresión aggiornada de una especificidad de lo humano con relación a la semiotización del cuerpo como vía expresiva del ser y su identidad. Ciertas prácticas vinculadas con lo arcaico y con lo trágico de la vida pondrían en juego invariantes antropológicas, pero bajo la premura actual de la obsolescencia y la avidez, que son los factores que permitirían comprender "la forma moda de todo" (26). Esta es un desbordamiento del consumismo como práctica porque ha de ser considerada en su dimensión de lógica social, según afirma Lipovetsky, algo a lo que nada ni nadie escapa y al que todo puede ser arrastrado en el flujo de atracción hacia lo nuevo.

En estas páginas se presentaron especulaciones que van desde la muerte de la moda a la moda como forma que lo abarca todo. Estas consideraciones no son nuevas, no son antitéticas, ni excluyentes, ni ajenas a otros planteamientos teóricos como, por ejemplo, los relativos a la muerte del arte con la contrapartida ampliamente discutida de la estetización de todo. Se parecen a la idea poética del sol que cae y muere al atardecer tiñendo con su color la totalidad del cielo en el momento preciso de su desaparición.

3 http://www.statisticbrain.com/tattoo-statistics/ Visitado 14 de agosto de 2015. 
¿Qué conexión tiene todo esto con el tatuaje contemporáneo? Probablemente en la expansión actual del tatuaje hay un factor imitativo como el que Simmel atribuía a la moda, una voluntad de emular una tendencia cada vez más extendida, máxime cuando su visibilización social y mediática es tan amplia, pero hay factores que laten en el tatuaje actual que parecen escapar a la lógica de la moda como sistema y que, en todo caso, lo asemejan más a ese estado de posmoda o de día después de la muerte de la moda que postula Saulquin. Ello es así porque el tatuaje escapa a la producción serial en tanto es siempre "un texto manuscrito" (Romano y Cebolla Lasheras 17), y aun cuando es posible encontrar personas con idéntico tatuaje, ya porque ha sido realizado por medio de la aplicación de calcos o porque se ha querido intencionalmente copiar el tattoo que lleva otra persona, el tatuaje conserva siempre la condición artesanal y amanuense ineludible en su ejecución. Sobre el trasfondo de la moda industrial que abastece de productos seriales que imitan a los modelos que solo están al alcance de algunos privilegiados, el tatuaje conservaría algo aurático, algo que lo hace único, irreductible a la copia mecanizada, es trabajo manual, es labor artesana hecha por una persona en contacto con el cuerpo de otra, insertando tinta bajo la piel. Si nos situamos ahora en el nuevo escenario del día después de la moda, el tatuaje se presentaría como un elemento congruente de las nuevas tendencias.

Jean Baudrillard se interrogaba en su obra El sistema de los objetos por las razones que hacen que en determinados momentos y para determinadas personas lo antiguo, lo artesanal, lo rústico y/o lo folclórico revistan un valor especialmente preciado. La pregunta tiene verdadero interés: “ ¿de dónde viene esa suerte de fenómeno de aculturación que lleva a los civilizados hacia fenómenos excéntricos en el tiempo y en el espacio a su propio sistema cultural, conduciéndolos hacia signos que son siempre anteriores?” (85). En su opinión, esos objetos están investidos de la cualidad de lo definitivo y lo auténtico, equivalen a un "retrato de familia" (85) y, por tanto, la posesión de esos objetos remitiría a una genealogía. Esos objetos funcionarían como indicios de una regresión hacia un tiempo mítico de origen que satisface la nostalgia por el pasado y la búsqueda de la autenticidad (la madre, la divinidad, la naturaleza, los saberes primitivos). Así, cargados de valor mitológico, transformados en leyenda, no constituyen "un discurso para los demás sino para sí mismo" (90), algo que se puede leer, por ejemplo, en el siguiente enunciado de una persona tatuada: "es una forma de expresión mía, para mí, no para nadie más [...] si alguien quiere saber qué significa mi tatuaje, entonces: pregúntame" (MTT3).

Cuando las exigencias de adaptación al modelo se relajan, como actualmente ocurre, emerge pues una pluralidad de expresiones entre las que lo vinculado con el registro del pasado resurge revalorizado y puede ser adoptado. Así, lo atávico entendido como lo que vuelve, como lo reprimido y no lo perimido, podría hacerse presente permitiéndonos salir de la posible dualidad entre moda o atavismo en nuestro intento por entender el fenómeno urbano del tatuaje. 


\section{FIGURA 4}

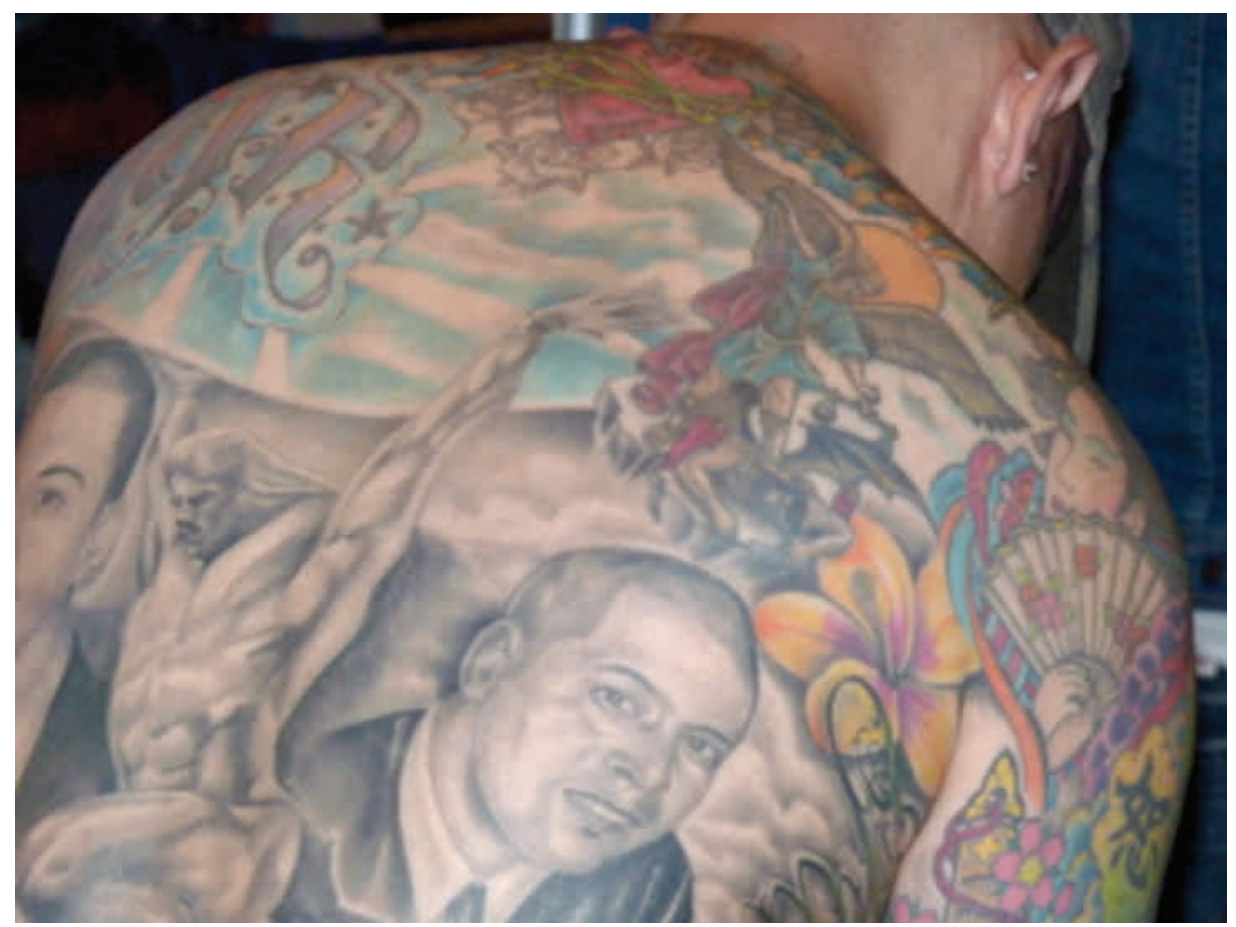

Fragmento de espalda densamente tatuada con iconografías variadas. Foto: Alejandra Walzer.

Tatuarse es sin dudas un acto que reviste cierta radicalidad incomparable con la que se involucra en la elección de una prenda de vestir que siempre es recambiable. Un hombre con muchos tatuajes dice al ser entrevistado: "al final yo creo que todos tenemos nuestra forma salvaje de querer expresar, te quieres expresar como sea” (HTT8). Pero esa expresión "salvaje" hecha de tinta en la piel, aunque pueda cubrirse con ropa, aunque se desvíe la mirada o se emplace en la espalda para no verla, allí permanece. Intervenir el cuerpo por medio de técnicas que son costosas, dolorosas y que además son definitivas hace sospechar que en el acto de tatuarse se expresa algo profundo que emerge como una fuerza potente: "el hacerte un tatuaje es una... hummm... para mí es bestia, para mí es bastante bruto y bastante bestia meterte aguja y tinta en tu cuerpo que no tenía por qué estar ahí, es una forma de expresar muy bruta. Es como la última forma de expresión, tú puedes pintar en mil sitios, pero la última forma de expresar sería en tu propio cuerpo" (MTT3), dice una joven.

El tatuaje como forma de comunicar con el cuerpo como medio expresivo de las características individuales, incluso como una expresión de esa tendencia a diseñarse a uno mismo, participaría de esa función primitiva del tatuaje en las sociedades no industrializadas y, de otro lado, aun integrado dentro de la idea del "todo moda" podría ser tenido por un modo de individuación y de rechazo de la masificación ma- 
nufacturada de la imagen personal. El tatuaje podría verse también como una de las múltiples expresiones de la era del consumo masivo en las que los factores imitación, prestigio y distinción van cediendo su lugar idealizado para ser suplantado por una demanda de autonomía. Dice un hombre tatuado: "es una necesidad muy grande de identificar lo individual, creo que es todo lo contrario de la necesidad de identificarte con un grupo de gente tatuada... me tatúo porque soy yo, porque es mi cuerpo y me tatúo lo que quiero" (HTT14).

En la sociedad planetaria que es al tiempo cercana y distante, real y virtual, nuestra vida se torna cada vez más anónima y mediada. No es extraño, pues, el auge emergente de lo local y lo individualizado. Es probable que, como escribe Régis Debray, haya relación entre la mundialización de los objetos y la tribalización de los sujetos (67).

En opinión de Alberto García-Alix, las razones se desdibujan a favor de lo mágico puesto que, en su opinión, el carácter "indeleble, junto al dolor causado por la rotura de la piel y la liberación de energía vital, la sangre, son las claves que han dado al tatuaje un significado místico, mágico e indudablemente hermético" (136).

Se han expuesto hasta aquí una serie de especulaciones y análisis en torno al fenómeno contemporáneo del tatuaje. Se ha abierto un abanico de posibles lecturas sobre las trayectorias, las razones, los sentidos, los modos. Si hay algo que resulta evidente es que el tatuaje contemporáneo se presenta como una práctica que semiotiza el cuerpo, inscribiendo textos que permiten leer en la piel de los sujetos nuestro tiempo histórico y social y nuestra condición de humanos.

\section{Referencias}

Atkinson, Michael. Tattooed. The Sociogenesis of a Body Art. Toronto, University of Toronto Press, 2003.

Augé, Marc. El antropólogo y el mundo global. Trad. Ariel Dilon. Buenos Aires, Siglo XXI Editores, 2014.

Barthes, Roland. El sistema de la moda y otros escritos. Trad. Carles Roche. Barcelona, Paidós, 2003.

Baudrillard, Jean. El sistema de los objetos. Trad. Francisco González Aramburu. México, D. F., Siglo XXI Editores, 1988.

Blanchard, Marc. "Post-Bourgeois Tattoo. Reflections on Skin Writing in Late Capitalist Societies". Visualizing theory. Selected essays from V.A.R 1990-1994. Ed. Lucien Taylor. New York, Routledge, 1994, pp. 287-300.

Debray, Régis. El arcaísmo posmoderno. Lo religioso en la aldea global. Trad. Horacio Pons. Buenos Aires, Manantial, 1996.

García-Alix, Alberto. Moriremos mirando. Textos completos. Madrid, La fábrica, 2008. Leopardi, Giacomo. Diálogo de la moda y de la muerte. Trad. Antonio Colinas. Buenos Aires, Taurus, 2014. 
Lévi-Strauss, Claude. La antropología frente a los problemas del mundo moderno. Trad. Agustina Blanco. Buenos Aires, Libros del zorzal, 2011.

Lipovetsky, Gilles. El imperio de lo efímero. La moda y su destino en las sociedades modernas. Trads. Felipe Hernández y Carmen López. Barcelona, Anagrama, 2011.

Maffesoli, Michel. El tiempo de las tribus. Trad. Bernardo Moreno Carrillo. Barcelona, Icaria, 1990.

---. El instante eterno. El retorno de lo trágico en las sociedades posmodernas. Trad. Virginia Gallo. Buenos Aires, Paidós, 2001.

---. El reencantamiento del mundo. Una ética para nuestro tiempo. Trad. Ariel Shalom. Buenos Aires, Dedalus, 2009.

Mead, Margaret. Cultura y compromiso. Estudio sobre la ruptura generacional. Barcelona, Gedisa, 2006.

Musafar, Fakir. Spirit + Flesh. New Mexico, Arena Editions, 2002.

Pitts, Victoria. In the Flesh. The Cultural Politics of Body Modifications. Nueva York, Palgrave Macmillan, 2003.

Romano, Anabella y María Julia Cebollas Lasheras. "El tatuaje en la cultura”. El tatuaje, un enigma a ser descifrado. Ensayo psicoanálitico. Eds. María Julia Cebolla et al. Buenos Aires, Letra Viva, 2012.

Saulquin, Susana. La muerte de la moda. El día después. Buenos Aires, Paidós, 2010. Segalen, Martine. Ritos y rituales contemporáneos. Trad. Alicia Martorell Linares. Madrid, Alianza, 2005.

Simmel, Georg. Sobre la aventura. Ensayos filosóficos. Trads. Gustau Muñoz y Salvador Mas. Barcelona, Península, 1988.

Thévoz, Michel. The Painted Body. The Illusions of Reality. New York, Rizzoli, 1984.

Vale V. y Andrea Juno. Modern Primitives: An Investigation of Contemporary Adornment and Ritual. San Francisco, RE/Search publications, 1989.

Walzer, Alejandra. "El arte en el discurso de los tatuadores". Arte, individuo y sociedad, vol. 27, n. ${ }^{\circ} 3,2015$, pp. 463-481.

---. "Tatuaje y significado: en torno al tatuaje contemporáneo". Revista de humanidades, n. ${ }^{\circ}$ 24, 2015, http://www.revistadehumanidades.com/articulos/87-tatuajey-significado-en-torno-al-tatuaje-contemporaneo

Walzer, Alejandra y Pablo Sanjurjo. "Los medios de comunicación y el tatuaje contemporáneo”. Communication \& Society, vol. 29, n. ${ }^{\circ}$ 1, 2016, pp. 69-81.

Enviado: 20 julio 2017

Aceptado: 18 julio 2018 